\title{
Phytochemical screening and antioxidant properties of stingless bee Geniotrigona thoracica propolis
}

\author{
Ainur Awanis Mohd Badiazaman, Nur Basyirah Md Zin, Aulia Rani Annisava, Nor Elani Mat Nafi, \\ Khamsah Suryati Mohd *
}

School of Agriculture Science and Biotechnology, Faculty of Bioresources and Food Industry, Universiti Sultan Zainal Abidin, Besut Campus, 22000 Besut, Terengganu, Malaysia

* Corresponding author: khamsahsuryati@unisza.edu.my

\section{Article history}

Received 28 December 2018

Revised 22 February 2019

Accepted 4 April 2019

Published Online 15 May 2019

\begin{abstract}
Propolis is a gum-like product that collected by bees from plants and it varies in colour range from light yellow to dark brown. The chemical composition of propolis depends on various factors such as vegetation, season and environmental conditions of the sample collection. The aim of the study was to determine the chemical profile and antioxidant properties of crude methanol extract of Geniotrigona thoracica propolis from five localities, namely Besut (BST), Dungun (DGN), Lundang (LDG), Tanah Merah (TM) and Gua Musang (GM). Phytochemical screening by thin layer chromatography (TLC) showed the presence of terpenoids, flavonoids, coumarins, essential oils and unsaturated and aromatic compounds. The extracts displayed different characteristics of chemical profile that varied from each other. The antioxidant properties of extracts were evaluated based on total phenolic content, total flavonoid content and 1,1-diphenyl-2-picrylhydrazyl (DPPH) free radicalscavenging activity. Propolis from Gua Musang (GM) exhibited the highest total phenolic content with $23.43 \pm 0.50 \mathrm{mg} \mathrm{GAE} / \mathrm{g}$ extract while propolis from Besut (BST) exhibited the highest total flavonoids content with $17.22 \pm 0.16 \mathrm{mg} \mathrm{QE} / \mathrm{g}$ extract and showed the lowest $\mathrm{IC}_{50}$ with $53 \mu \mathrm{g} / \mathrm{mL}$ for DPPH radical scavenging activities. As a result, Geniotrigona thoracica from Besut (BST) could be considered as a good source of antioxidant due to its antioxidant properties.
\end{abstract}

Keywords: Stingless bee, propolis, Geniotrigona thoracica,TLC profiling, antioxidant

\section{INTRODUCTION}

Propolis is a gum-like product that collected by bees from plants and it varies in color range from light yellow to dark brown (Shittu et $a l ., 2015)$. Bees apply propolis in a thin layer on the inner walls of their hives. It is used to block holes and cracks, repair combs, reinforce the thin edges of the comb and make the entrance of the hive to be weatherproof or easier to protect (Bankova et al., 2000). Propolis acts as defensive antimicrobial substances in their hives and is used as a building material (Popova et al., 2013). Propolis also acts as an "embalming substance" because it can cover the hive with invaders that have been killed by bees but cannot transport out of the hive (Ghisalberti, 1979). Propolis has a lipophilic properties that is hard and unbreakable when cold but soft, flexible and very sticky when warm (Umthong et al., 2011; Marcucci, 1995; Fokt et al., 2010). Generally, propolis contains $50-60 \%$ resins and balms, 30-40\% waxes, $5-10 \%$ essential oils, $5 \%$ pollen grains, microelements and vitamins (Rufatto et al., 2017).

The chemical composition of propolis is varied and depending on various factors such as vegetation, season and environmental conditions of the sample collection, leading to difficulty for standardization (Sforcin \& Bankova, 2011; Barlak et al., 2011; Bankova, 2005). Thus, constituents of propolis from different places may be different. For example in Europe, North America, New Zealand and temperate zones of Asia, propolis consists of flavonoids, phenolic acids and their esters, meanwhile in Greece (Popova et al., 2010; Celemli et al., 2013) and Switzerland (Bankova et al., 2002), propolis is highly composed of diterpenoids. Propolis from Brazil, mainly in the south-eastern region is consisted with the presence of common and abundant chemical constituents prenylated phenylpropanoids, prenylated $p$-coumaric acids, acetophenones, diterpenic acids, and caffeoylquinic acids (Bankova, 2005; Bankova et al., 2000; Falcão et al., 2013). The flavonoids kaempferide, isosakuranetin and some of kaempferol are found in other Brazilian propolis (Park et al., 2002). Meanwhile, the content of Cuban propolis is comprised of polyisoprenylated benzophenones, more specifically nemorosone, and a mixture of xanthochymol and guttiferone $\mathrm{E}$ (Bankova, 2005; Cuesta-Rubio et al., 2002), making it to be chemically distinct from European and Brazilian propolis.

Propolis has numerous pharmacological activities such as antioxidant, antibacterial, anticancer, antifungal, anti-inflammatory, antiviral, and antidiabetic due to its various and complex chemical compositions (Bankova, 2009). Previous study by Ibrahim et al. (2016) reported that propolis produced from stingless bee Heterotrigona itama and Geniotrigona thoracica could inhibit the growth of Staphylococcus aureus better than Gram-negative (Escherichia coli and Salmonella typhi) bacteria. Propolis produced by stingless bee Tetragonula carbonaria from Australia could also inhibit the growth of S. aureus (Massaro et al., 2014). Chemical compounds isolated from Brazilian propolis which are triterpenoids, 
melliferone, moronic acid, anwuweizonic acid, betulinic acid and four known aromatic compounds have been tested for anti-HIV activity in H9 lymphocytes and the result showed that moronic acid has significant anti-HIV activity (Ito et al., 2001). Amoros et al. (1992) revealed that major flavonoids of propolis like flavonols and flavones showed antiviral activity against HSV-1.

A free radical is any species that contains one or more unpaired electrons, in which an unpaired electron is in atomic or molecular orbitals (Halliwell et al., 1995). Free radicals and reactive oxygen species (ROS) such as hydrogen peroxide $\left(\mathrm{H}_{2} \mathrm{O}_{2}\right)$, superoxide anion $\left(\mathrm{O}_{2}^{-}\right)$, and hydroxyl ion $\left(\mathrm{HO}^{-}\right)$, as well as reactive nitrogen species (RNS), especially nitric oxide (NO) can be generated through the process of cellular metabolism and the exposure to the exogenous agents like UV, toxins and drugs (Sosa et al., 2013; Salmon et al., 2004; Viuda-Martos et al., 2008). Numerous systemic and cellular dysfunctions such as hyperglycaemia, dyslipidemia, advanced glycation end products, endoplasmic reticulum (ER) stress, nitric oxide synthase and lipid peroxides are responsible for over production of reactive oxygen species (ROS) that will induce the oxidative stress in the cells and plasma (Henriksen et al., 2011). Oxidative stress can potentially distribute in causing various diseases in human such as neurodegenerative or cardiovascular disease, diabetes, cancer and atheroslerocis (Silva-Carvalho et al., 2015). An antioxidant can be defined as any substance that inhibits or delays oxidative damage to a target molecule (Yamagishi \& Matsui, 2011). Antioxidant compounds such as polyphenols, phenolic acid and flavonoids can scavenge free radicals like peroxide, hydroperoxide or lipid peroxyl, causing inhibition of oxidative mechanism which leads to degenerative mechanism (Wu et al., 2011). Portugese propolis has the potential to protect human erythrocytes from free radical damages by decreasing the lipid peroxidation due to its powerful antioxidant agent that can be used to prevent oxidative stress and thus, maintaining the structural and functional integrity of the cells (Valente et al., 2011). Red propolis from China contains high amounts of galangin and phenethyl caffeate which lead to higher antioxidant activity (Kumazawa et al., 2004). Galangin and phenetyhl caffeate are reported to be responsible for antioxidant activity (Hatano et al., 2012). Hence, the present study was designed to screen the phytochemicals as well as to evaluate the antioxidants activity, total phenolic contents and total flavonoid contents in stingless bee Geniotrigona thoracica propolis from different localities namely as Besut (BST), Dungun (DGN), Lundang (LDG), Tanah Merah (TM), and Gua Musang (GM).

\section{EXPERIMENTAL}

\section{Materials}

Gallic acid, quercetin, trolox, Folin-Ciocalteu phenol reagent, aluminium chloride, potassium acetate, sodium carbonate solution, 1,1-diphenyl-2-picrylhydrazyl (DPPH), dimethyl sulfoxide (DMSO), methanol, sulphuric acid, ethanol, glacial acetic acid, toluene, ethyl acetate, and TLC silica gel $60 \mathrm{~F}_{254}$ plate of $0.05 \mathrm{~mm}$ thickness were purchased from Merck

\section{Propolis samples}

Propolis samples from stingless bee were collected from hives of five different localities which were Besut $\left(\mathrm{N}^{\circ} 45^{\prime} 34.6^{\prime \prime} \mathrm{N} 102^{\circ} 38^{\prime}\right.$ $\left.18.5^{\prime \prime} \mathrm{E}\right)$, Dungun (N 04 $\left.42^{\prime} 43.7^{\prime \prime} \mathrm{N} 103^{\circ} 23^{\prime} 49.3^{\prime \prime} \mathrm{E}\right)$, Lundang(N

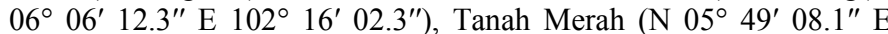
$102^{\circ} 06^{\prime} 24.6^{\prime \prime}$ ) and Gua Musang (N $05^{\circ} 09^{\prime} 12.5^{\prime \prime} \mathrm{E} 101^{\circ} 58^{\prime} 33.8^{\prime \prime}$ ).

\section{Preparation of extract}

The 30 grams of powdered propolis was extracted using maceration process with $70 \mathrm{~mL}$ of methanol for at least 3 days. The extract was filtered by using Whatman No.1 filter paper. The extract was dried under pressure using rotatory evaporator and kept in $-20^{\circ} \mathrm{C}$ prior for further analysis. The propolis extract was coded as following; Besut (BST), Dungun (DGN), Lundang (LDG), Tanah Merah (TM) and Gua Musang (GM).

\section{Phytochemical screening by thin layer chromatography}

G. thoracica propolis from different localities were screened to identify the presence of various classes of compound according to the standard screening method by Trease and Evans (1983) with slight modification using thin layer chromatography (TLC) silica gel $60 \mathrm{~F}_{254}$ plate of $0.05 \mathrm{~mm}$ thickness. The crude extracts were accurately weighed at $30 \mathrm{mg}$ and dissolved in $1 \mathrm{~mL}$ of methanol, followed by sonication for $30 \mathrm{~min}$ and centrifugation for $10 \mathrm{~min}$ at $140 \mathrm{rpm}$. The development of plate was done in a glass twin-through chamber using toluene: ethyl acetate: acetic acid: methanol (8: 2: 0.1: $0.2 \mathrm{v} / \mathrm{v} / \mathrm{v} / \mathrm{v})$ as a mobile phase. After development, the plate was dried with heat gun and visualized at $254 \mathrm{~nm}$ and $366 \mathrm{~nm}$, and then sprayed with various chemical reagents such as vanillin-sulphuric acid and iodine for detection of the respective classes of compound.

\section{Determination of total phenolic content (TPC)}

Total phenolic content was determined using the Folin-Ciocalteu reagent according to the method developed by Singleton and Rossi (1965) with slight modification. Briefly, $100 \mu \mathrm{L}$ of the each sample was added into microtubes and followed by adding $200 \mu \mathrm{L}$ of FolinCiocalteu reagent and was vortex thoroughly. Next, $800 \mu \mathrm{L}$ of 700 $\mathrm{mM} \mathrm{Na} \mathrm{CO}_{3}$ was added into the mixture and incubated at room temperature for $2 \mathrm{hrs}$. After incubation, $200 \mu \mathrm{L}$ of sample was transferred into the 96-well microplate and the absorbance was read at $765 \mathrm{~nm}$ using Elisa reader spectrophotometer. Gallic acid was used as a positive control with concentration that ranged from 60 to 200 $\mathrm{mg} / \mathrm{mL}$. The total phenolics content was measured in triplicate. The results were expressed as $\mathrm{mg}$ of gallic acid equivalents (GAE) per $\mathrm{g}$ of extract.

\section{Determination of total flavonoid content (TFC)}

Total flavonoids content was determined by aluminium chloride using method described by Woisky and Salatino (1998) with slight modification. Briefly, $140 \mu \mathrm{L}$ of each sample, $150 \mu \mathrm{L}$ of aluminium chloride solution, $150 \mu \mathrm{L}$ potassium acetate solution and $260 \mu \mathrm{L}$ of distilled water were added and mixed well. After incubation at room temperature for $30 \mathrm{~min}$, the samples were transferred into the 96 -well plate. The absorbance was read at $415 \mathrm{~nm}$ with Elisa reader spectrophotometer. The calibration curve was constructed with serial dilution of quercetin in concentration that ranged from 0.7815 to 100 $\mathrm{mg} / \mathrm{mL}$. The results were expressed as $\mathrm{mg}$ of quercetin equivalents (QE) per g of extract.

\section{DPPH free radical scavenging activity}

The antioxidant activity of the extracts was determined using the DPPH free radical scavenging assay described by Brand-Williams et al. (1995) with some modification. Quercetin and trolox were used as a positive control. Briefly, $5 \mathrm{mg}$ of quercetin, trolox standard and extracts were dissolved in $1 \mathrm{~mL}$ of dimethyl sulfoxide (DMSO). About $25 \mu \mathrm{L}$ of standard and extracts were added into the 96-well plate. Serial dilution was performed from stock solution of standard and extracts to produce final concentrations of $7.1825,15.625$, $31.125,62.5,125,250$ and $500 \mu \mathrm{g} / \mathrm{mL}$. Next, $200 \mu \mathrm{L}$ of $1 \mathrm{mM} \mathrm{DPPH}$ in methanol solution was added into each well and left at room temperature in the dark condition for $30 \mathrm{~min}$ to complete the reaction. After incubation period, the absorbance was measured at $517 \mathrm{~nm}$ using Elisa reader spectrophotometer. The blank sample used was the solution comprised of $50 \mu \mathrm{L}$ DMSO and $200 \mu \mathrm{L}$ of $1 \mathrm{mM}$ DPPH. The percentage of inhibition was calculated using the equation (1).

$$
\text { Inhibition } \%=\left[(\text { A Blank } \text { Asample }) / A_{\text {Blank }}\right] \times 100 \%
$$

ABlank is the absorbance of DMSO with $1 \mathrm{mM}$ of DPPH in methanol solution while Asample is the absorbance of the extracts and positive control solution. The lower absorbance and the decrease intensity of the purple to yellow colour were indicated for a higher scavenging activity. The radical scavenging activities of crude extracts were interpreted by $\mathrm{IC}_{50}$ values. The $\mathrm{IC}_{50}$ is a concentration that has the ability to scavenge the $50 \%$ of DPPH free radical. 


\section{Statistical analysis}

Assays were performed in triplicate and the results were expressed as mean values with standard deviations (SD). The significant differences, represented by letters, were obtained by a one-way analysis of variance (ANOVA), followed by Tukey's honestly significant difference (HSD) post hoc test $(\mathrm{p}<0.05)$ using Statistical Package for Social Science (SPSS) version 24.0 (Armonk, NY, USA).

\section{RESULTS AND DISCUSSION}

\section{Phytochemical screening by thin layer chromatography analysis}

Phytochemicals are non-nutritive chemical compounds derived from plants which have some disease preventative properties. They are non-essential nutrients which are not necessarily required by the human body for sustaining life (Kalaiselvi et al., 2016) Phytochemical screening is the earlier step in finding out the chemical constituents presented in the plants, which are helpful for determination of quantitative of those chemical constituents. In the present study, the phytochemical screening of the stingless bee $G$. thoracica propolis from different locations was carried out using thin layer chromatography (TLC) analysis. TLC analysis is helpful for detection of various classes of chemical compound that presented in the samples. There were two spray reagents used for detection of compound which were vanillin-sulphuric acid and iodine. Vanillinsulphuric acid is a universal reagent that used to detect compound from group of amines, amino acids, higher alcohols, phenols and essential oils. Meanwhile, iodine is used for detection of many organic compounds because iodine has a high affinity for both unsaturated and aromatic compounds like phenolic steroid, ester, alkaloids and polycylic compounds.

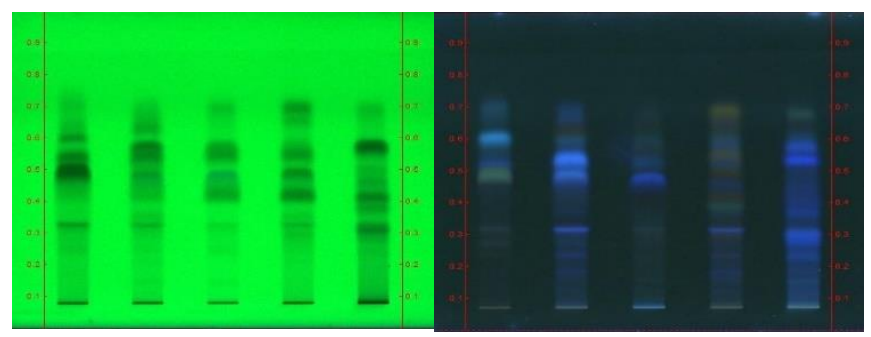

(a) BST DGN LDG TM GM

(b) BST DGN LDG TM GM

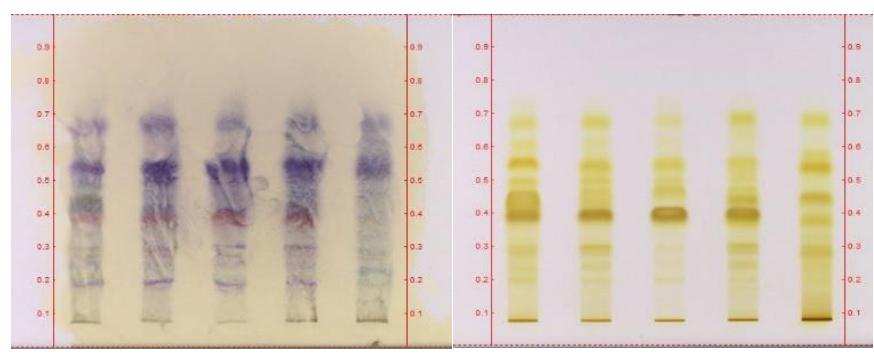

(c) BST DGN LDG TM GM

(d) BST DGN LDG TM GM

Fig. 1 TLC photodocumentation of methanolic extract of $G$. thoracica propolis from different locations by visualization (a) UV $254 \mathrm{~nm}$ (b) UV $366 \mathrm{~nm}$ (c) Post derivatisation vanillin-sulphuric acid (d) Post derivatisation iodine vapour.

Based on Fig. 1 (a) and (b), the compounds were visible when TLC plate was visualized under short and long waves of UV light. Coumarins (light blue) were presented in all propolis samples when being visualized under $366 \mathrm{~nm}$ UV light. When the TLC plate was sprayed with vanillin as shown in Fig. 1 (c), terpenoids (purple) were presented in all propolis samples while flavonoids (pink) were only absent in sample from GM and essential oils (brown) were only presented in sample from BST. In Fig. 1 (d), the unsaturated and aromatic compounds (yellow brown) were detected in all propolis samples when the plate was stained with iodine vapour. Overall, propolis from BST showed the presence of all compounds and contained more chemical compositions compared to propolis from other locations. This result of present study was coincided with the study reported by Ibrahim et al. (2016) that conducted on the phytochemical screening of propolis produced by stingless bee $H$. itama and G. thoracica. Propolis from G. thoracica showed the presence of terpenoids, flavonoids, essential oil, unsaturated and aromatic compounds. Previous study reported that phytochemical screening of propolis from $G$. thoracica revealed the presence of chemical constituents like terpenoids, flavonoids and stilbenes (Ibrahim et al., 2016).

The differences in phytochemical screening of compound in $G$. thoracica propolis might due to the different geographical and locations of the collected samples. A previous study by Milojković Opsenica et al. (2016) stated that chemical composition of propolis was depended on the geographical, plant source in the area from which it was collected, collecting seasons and climate factors, leading to difficulty in standardization. For example, propolis from Europe and China possessed many types of flavonoids and phenolic acid ester (Bankova et al., 2000) while in Brazilian propolis, the major components were terpenoids and prenylated derivatives of $p$-coumaric acids (Marcucci \& Bankova, 1999; Tazawa et al., 1998; Tazawa et al., 1999).

Table 1 Phytochemical test of the methanolic extract of $G$. thoracica propolis from different locations of Besut (BST), Dungun (DGN), Lundang (LDG), Tanah Merah (TM) and Gua Musang (GM).

\begin{tabular}{|c|c|c|c|c|c|c|c|}
\hline Constituents & $\begin{array}{l}\text { Colour } \\
\text { detected }\end{array}$ & $\stackrel{\mathfrak{m}}{\mathfrak{m}}$ & ত্ & ن & $\sum$ & $\sum_{W}$ & $\begin{array}{c}\text { Chemical } \\
\text { /Spray } \\
\text { reagent }\end{array}$ \\
\hline Terpenoids & Purple & + & + & + & + & + & $\begin{array}{l}\text { Vanillin- } \\
\text { sulphuric } \\
\text { acid }\end{array}$ \\
\hline Flavonoids & Pink & + & + & + & + & - & $\begin{array}{l}\text { Vanillin- } \\
\text { sulphuric } \\
\text { acid }\end{array}$ \\
\hline Coumarins & Light blue & + & + & + & + & + & $\begin{array}{l}\text { UV } 366 \\
\mathrm{~nm}\end{array}$ \\
\hline $\begin{array}{l}\text { Essential } \\
\text { oils }\end{array}$ & Brown & + & - & - & - & - & $\begin{array}{l}\text { Vanillin- } \\
\text { sulphuric } \\
\text { acid }\end{array}$ \\
\hline $\begin{array}{l}\text { Unsaturated } \\
\text { and } \\
\text { aromatic } \\
\text { compounds }\end{array}$ & $\begin{array}{l}\text { Yellow } \\
\text { brown }\end{array}$ & + & + & + & + & + & lodine \\
\hline
\end{tabular}

Remarks: +, detected; -, not detected

\section{Total phenolic content}

Polyphenols gave benefit on human health in various ways. It has been reported to exhibit anti-carcinogenic, anti-ulcer, anti-thrombic, anti-atherogenic, anti-inflammatory, anti-microbial, immune modulating, vasolidatory and analgesic effects (Wollgast \& Anklam, 2000). The beneficial effects of polyphenols on human health might due to their free radical scavenging activity which could block the deleterious action of these molecules on human cells (Bobo-García et al., 2015). The total phenolics content in G. thoracica propolis extracts was based on Folin-Ciocalteu method. The FC reagent was consisted of phosphomolybdic/ phosphotungstic acid complexes. The method worked based on the transfer of electron from phenolic compounds in alkaline medium to form a blue chromophore consisting of a phosphotungstic/ phosphomolybdenum complex, in which the maximum absorption was depended on the concentration of the phenolic compounds (Singleton \& Rossi, 1965). The total phenolics content in $G$. thoracica propolis extracts were different according to the location of collected sample (Table 2). The total phenolics content of $G$. thoracia propolis were varied from $9.23 \pm$ 0.37 to $23.43 \pm 0.50 \mathrm{mg} \mathrm{GAE} / \mathrm{g}$ extract. Propolis from GM showed the high amount of this compound with $23.43 \pm 0.50 \mathrm{mg}$ GAE/g extract while propolis from LDG showed the lowest value of total phenolics content with $9.23 \pm 0.37 \mathrm{mg} \mathrm{GAE} / \mathrm{g}$ extract. There were significant differences in total phenolics content when compared 
propolis samples from different locations (one-way ANOVA; $\mathrm{p}<$ 0.05). Study by Moreira et al. (2008) previously reported that propolis from Borneo exerted the highest total phenolics content with $329.00 \pm$ $0.01 \mathrm{mg} \mathrm{GAE} / \mathrm{g}$, twice the value in Fundão propolis (151.00 \pm 0.01 mg GAE/g). Another study by Kumazawa et al. (2004) stated that polyphenol content from Europe propolis (Bulgaria and Hungary) and China (Hebei, Hubei and Zhejiang) had the value that ranged from $200-300 \mathrm{mg} / \mathrm{g}$ of extract while Thailand propolis exerted the lowest phenolics content by $31.2 \pm 0.7 \mathrm{mg} / \mathrm{g}$ of extract. The variations in value of polyphenol content in propolis might be due to the origin of the raw material (Machado et al., 2016).

\section{Total flavonoid content}

Propolis has a wide variety of phenolic compounds, mainly of flavonoids. Aluminium nitrate colorimetric method was used to study the total flavonoids content in G. thoracia propolis. Aluminium nitrate would form acid stable complex when reacted with C-4 keto groups and either the C-3 or C-5 hydroxyl group of flavones and flavonols. It would also form acid labile complexes when reacted with the orthodihydroxyl groups in the A- or B- ring of flavonoid (Bhaigyabati et $a l ., 2014)$. Quercetin was used as a positive control due to the fact that it was a common compound of flavonoid group found in propolis. Due to the presence of its functional hydroxyl group, quercetin had strong absorbance at $415 \mathrm{~nm}$ even though the concentrations were lower than $100 \mathrm{ppm}$ (Mohammadzadeh et al., 2007). Based on Table 2, total flavonoids content of $G$. thoracica propolis were varied from $9.52 \pm 0.54$ to $17.22 \pm 0.16 \mathrm{mg} \mathrm{QE} / \mathrm{g}$ extract with the lowest value of flavonoids content was found in propolis from DGN and the highest one for propolis from BST. There were significant differences in total flavonoids content between propolis from LDG and GM when compared with BST, DGN and TM (one-way ANOVA; $\mathrm{p}<0.05$ ).

Table 2 Total phenolic and flavonoid contents determined by Folin Ciocalteu and aluminium nitrate colorimetric methods.

\begin{tabular}{lll}
\hline $\begin{array}{l}\text { Localities of G. } \\
\text { thoracica } \\
\text { propolis }\end{array}$ & $\begin{array}{l}\text { Total phenolic } \\
\text { contents } \\
\text { mean } \pm \text { SD } \\
\text { (mg GAE/g extract) }\end{array}$ & $\begin{array}{l}\text { Total flavonoid } \\
\text { contents } \\
\text { mean } \pm \text { SD } \\
\text { (mg QE/g extract) }\end{array}$ \\
\hline BST & $13.07 \pm 0.62^{\mathrm{b}}$ & $17.22 \pm 0.16^{\mathrm{d}}$ \\
DGN & $15.27 \pm 0.12^{\mathrm{c}}$ & $9.52 \pm 0.54^{\mathrm{a}}$ \\
LDG & $9.23 \pm 0.37^{\mathrm{a}}$ & $13.34 \pm 0.20^{\mathrm{c}}$ \\
TM & $17.96 \pm 0.64^{\mathrm{d}}$ & $11.33 \pm 0.03^{\mathrm{b}}$ \\
GM & $23.43 \pm 0.50^{\mathrm{e}}$ & $14.06 \pm 0.36^{\mathrm{c}}$ \\
\hline
\end{tabular}

Means were compared by using one-way ANOVA with post hoc multiple comparisons. In each column, values with different letters (superscripts) were indicated for significant differences $(p<0.05)$.

Previous study by Ahn et al. (2007) reported that propolis from different locations in China showed variations in the total flavonoids content. Propolis from Gansu had the highest flavonoids content by $188 \pm 6.6 \mathrm{mg} / \mathrm{g}$ of extract compared to propolis from Yunnan which had the lowest flavonoids content with $8.3 \pm 3.7 \mathrm{mg} / \mathrm{g}$ of extract. Another study by Kumazawa et al. (2004) stated that propolis from Hungary showed the highest flavonoids content with value $176 \pm 1.7$ $\mathrm{mg} / \mathrm{g}$ of extract while propolis from Thailand had the lowest flavonoids content with $2.5 \pm 0.8 \mathrm{mg} / \mathrm{g}$ extract. The variations in total flavonoids content in propolis might be due to the differences in the preferred regional plants collected by bees. Flavonoids and other phenolic substances might act as preventive role in the development of cancer and heart disease (Kahkonen et al., 1999).

\section{DPPH free radical scavenging activity}

Propolis was considered to be an abundant source of antioxidant activity due to the presence of phenolics and flavonoids compounds. The divergent varieties of propolis found throughout the world showed the variations in their antioxidant activity. Numerous studies have been conducted to determine the antioxidant activity in propolis due to its antioxidant potential. The antioxidant activity in $G$. thoracica propolis in the present study was determined by using DPPH scavenging method. The method was relied on the electron transfer as it could assesses the scavenging potential of a given substances (Garcia et al., 2012). The method would give an intense violet solution which was stable at room temperature. The colour of the purple solution would change to colorless or light yellow when DPPH solution was mixed with the tested compounds. The changes of the colour would indicate the free radical that has been scavenged (Kedare \& Singh, 2011). To evaluate the antioxidant activity, the concentration of propolis used in this study was varied from 7.8125 to $500 \mu \mathrm{g} / \mathrm{mL}$ with quercetin and trolox that were served as standards. From Fig. 2, propolis from BST exhibited the highest percentage of inhibition, followed closely by TM while LDG exerted the lowest percentage of inhibition.

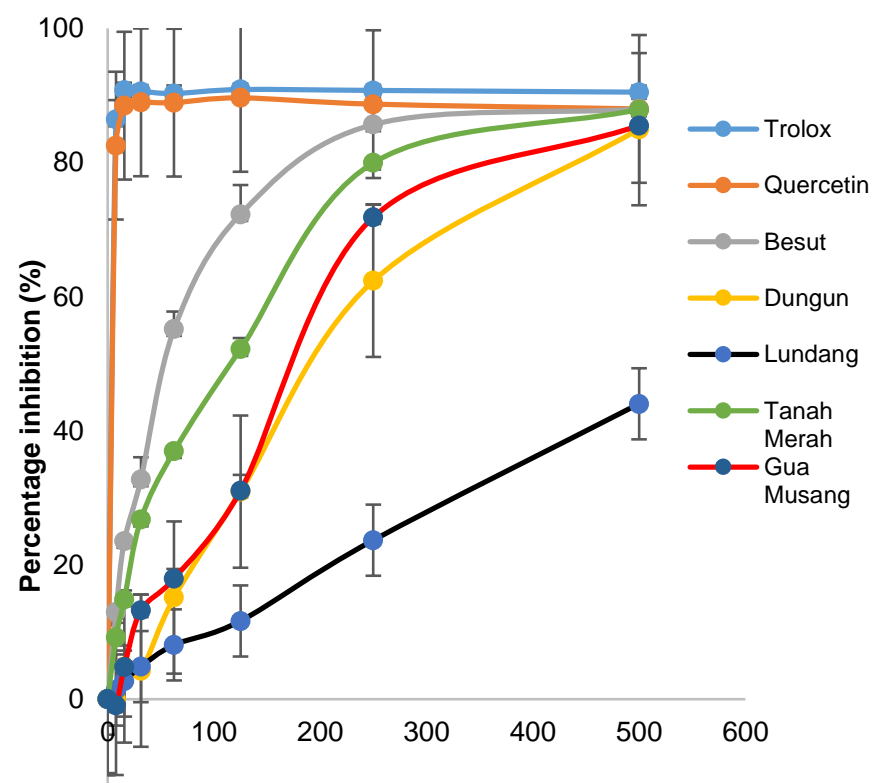

$-20$

Concentration of samples $(\mu \mathrm{g} / \mathrm{mL})$

Fig. 2 Percentage of inhibition of DPPH free radical scavenging activity at different concentrations of $G$. thoracica propolis from Besut (BST), Dungun (DGN), Lundang (LDG), Tanah Merah (TM) and Gua Musang (GM).

Besides percentage of inhibition, $\mathrm{IC}_{50}$ values could also be determined from this assay. $\mathrm{IC}_{50}$ is defined as the concentration of extract required to scavenge the DPPH free radical by $50 \%$. Propolis from BST showed lowest $\mathrm{IC}_{50}$ with $53 \mu \mathrm{g} / \mathrm{mL}$ while the highest $\mathrm{IC}_{50}$ was showed by propolis from DGN with $190 \mu \mathrm{g} / \mathrm{mL}$ and propolis from LDG was inactive. The lower the $\mathrm{IC}_{50}$, the greater the radical scavenging activity. Thus, propolis from BST had the highest radical scavenging and antioxidant activities. These variations might due to the differences of chemical composition in the propolis extracts (Socha et al., 2015). Study by Ibrahim et al. (2016) on the effect of propolis produced from stingless bee $H$. itama and G. thoracica towards the free radical scavenging activity showed that propolis from H. itama had stronger antiradical activity compared to propolis from G. thoracia. Ethanolic extracts of propolis from Italy and Russian possessed similar antioxidant activity due to the similar composition of phenolic compounds while Brazilian propolis had weak antioxidant activity due to low phenolic composition (Fabris et al., 2013). The free radical scavenging activity was appeared to correlate with the presence of phenolic compounds and in particular to flavonoids which were the most abundant and effective antioxidant compounds (Kumazawa et al., 2004; Moreno et al., 2000; Isla et al., 2001). Previous study by Yang et al. (2011) found that antiradical activity was depended on the compound presented in the propolis for example $p$-coumaric acid and isoferulic acids exerted higher antiradical activity towards DPPH. Propolis that collected from Anhui, China inhibited strong free radical scavenging activity and ferric reducing activity due to the presence of caffeic acid, phenethyl caffeate, cinnamyl caffeate 
and benzyl caffeate (Yang et al., 2011). Another study reported that methanolic extracts of Algerian propolis had strong scavenging activity and ferric reducing activity, those activities were influenced by the presence of high amounts of caffeic acid esters and flavanones, kaempferol and galanggin (Piccinelli et al., 2013). Ethyl acetate extract of Kangaroo Island propolis which enriched with stilbenes also possessed a stronger scavenging activities (Abu-Mellal et al., 2012). The chemical structures of compound were also contributed to the difference in antioxidant and antiradical acitivities of propolis extracts. The most active flavonoids, which were quercetin and kaempferol contained five or four hydroxyl groups which contributed to the antioxidant properties while galangin was less active with only three hydroxyl groups (Kumazawa et al., 2004; Ahn et al., 2009).

\section{CONCLUSION}

In this study, the results of phytochemical screening and determination of total phenolic content, total flavonoids content and their antioxidant activity in methanolic extracts of $G$. thoracica propolis from different locations were presented. G. thoracica from Besut (BST) showed various compounds in phytochemical screening and exerted highest total flavonoids content, as well as exhibited lowest $\mathrm{IC}_{50}$ for DPPH free radical scavenging activity which indicated for a good source of antioxidant due to its antioxidant properties. Further investigation on identification of the compounds in propolis with their biological activity should be carried out for propolis standardization.

\section{ACKNOWLEDGEMENT}

This study was funded by Fundamental Research Grant Scheme (FRGS) with Project Code FRGS/1/2017/WAB01/UNISZA/021/.

\section{REFERENCES}

Abu-Mellal, A., Koolaji, N., Duke, R. K., Tran, V. H., \& Duke, C. C. (2012). Prenylated cinnamate and stilbenes from Kangaroo Island propolis and their antioxidant activity. Phytochemistry, 77, 251-259.

Ahn, M. R., Kumazawa, S., Usui, Y., Nakamura, J., Matsuka, M., Zhu, F., \& Nakayama, T. (2007). Antioxidant activity and constituents of propolis collected in various areas of China. Food Chemistry, 101(4), 1383-1392.

Ahn M. R., Kunimasa, K., Kumazawa, S., Nakayama, T., Kaji, K., Uto, Y., Hori, H., Nagasawa, H., \& Ohta, T. (2009). Correlation between antiangiogenic activity and antioxidant activity of various components from propolis. Molecular Nutrition \& Food Research, 53, 643-651.

Amoros, M., Simõs, C. M. O., Girre, L., Sauvager, F., \& Cormier, M. (1992) Synergistic effect of flavones and flavonols against herpes simplex virus type 1 in cell culture. Comparison with the antiviral activity of propolis. Journal of Natural Products, 55(12), 1732-1740.

Bankova, V. S., Castro, S. L. D., \& Marcucci, M. C. (2000). Propolis: recent advances in chemistry and plant origin. Apidologie, 31, 3-15.

Bankova, V., Popova, M., Bogdanov. S., \& Sabatini, A. G. (2002). Chemical composition of European propolis: Expected and unexpected results. Zeitschrift für Naturforschung C, 57, 530-533.

Bankova, V. (2005). Chemical diversity of propolis and the problem of standardization. Journal of Ethnopharmacology, 100(1-2), 114-117.

Bankova, V. (2009). Chemical diversity of propolis makes it a valuable source of new biologically active compounds. Journal of ApiProduct and ApiMedical Science, 1(2), 23-28.

Barlak, Y., De ger, O., Olak , M.C., Karatayli, S. C., Bozdayi, A. M., \& Y“ucesan, F. (2011). Effect of Turkish propolis extracts on proteome of prostate cancer cell line. Proteome Science, 9, 74

Bhaigyabati, T., Devi, P. G., \& Bag, G. C. (2014). Total flavonoid content and antioxidant activity of aqueous rhizome extract of three hedychium species of Manipur Valley. Research Journal of Pharmaceutical, Biological, and Chemical Sciences, 5(5), 970-6.

Bobo-García, G., Davidov-Pardo, G., Arroqui, C., Vírseda, P., Marín-Arroyo, M. R., \& Navarro, M. (2015). Intra-laboratory validation of microplate methods for total phenolic content and antioxidant activity on polyphenolic extracts, and comparison with conventional spectrophotometric methods. Journal of the Science of Food and Agriculture, 95(1), 204-209.
Brand-Williams, W., Cuvelier, M. E. \& Berset, C. (1995). Use of free radical method to evaluate antioxidant activity. LWT-Food Science and Technology, 28, 25 - 30.

Celemli, O. G., Hatjina, F., Charistos, L., Schiesser, A., \& Ozkirim, A. (2013). More insight into the chemical composition of Greek propolis; differences and similarities with Turkish propolis. Zeitschrift fur Naturforschung, 68(11-12), 429-438

Cuesta-Rubio, O., Frontana-Uribe, B. A., Ramírez-Apan, T., \& Cárdenas, J. (2002). Polyisoprenylated benzophenones in Cuban propolis: Biological activity of nemorosone. Zeitschrift für Naturforschung C, 57(3-4), 372378.

Fabris, S., Bertelle, M., Astafyeva, O., Gregoris, E., Zangrando, R., Gambaro, A., Lima, G. P., \& Stevanato, R. (2013). Antioxidant properties and chemical composition relationship of Europeans and Brazilians propolis. Pharmacology \& Pharmacy, 4(01), 46.

Falcão, S. I., Vale, N., Gomes, P., Domingues, M. R., Freire, C., Cardoso, S. M., \& Vilas-Boas, M. (2013). Phenolic profiling of Portuguese propolis by LC-MS spectrometry: Uncommon propolis rich in flavonoid glycosides. Phytochemical Analysis, 24(4), 309-318.

Fokt, H., Pereira, A., Ferreira, A. M., Cunha, A., \& Aguiar, C. (2010). How do bees prevent hive infections? The antimicrobial properties of propolis. Current Research, Technology and Education Topics in Applied Microbiology and Microbial Biotechnology, 1, 481-493.

Garcia, E. J., Oldoni, T. L. C., Alencar, S. M. D., Reis, A., Loguercio, A. D., \& Grande, R. H. M. (2012). Antioxidant activity by DPPH assay of potential solutions to be applied on bleached teeth. Brazilian Dental Journal, 23(1), 22-27.

Ghisalberti, E. L. (1979). Propolis: A review. Bee World, 60(2), 59-84.

Halliwell, B., Murcia, M. A., Chirico, S., \& Aruoma, O. I. (1995). Free radicals and antioxidants in food and in vivo: what they do and how they work. Critical Reviews in Food Science \& Nutrition, 35(1-2), 7-20.

Hatano, A., Nonaka, T., Yoshino, M., Ahn, M. R., Tazawa, S., Araki, Y., \& Kumazawa, S. (2012). Antioxidant activity and phenolic constituents of red propolis from Shandong, China. Food Science and Technology Research, 18(4), 577-584.

Henriksen, E. J., Diamond, S. M. K., \& Marchionne, E. M. (2011). Oxidative stress and the etiology of insulin resistance and type 2 diabetes. Free Radical Biology and Medicine, 51, 993-999.

Ibrahim, N., Zakaria, A. J., Ismail, Z., \& Mohd, K. S. (2016). Antibacterial and phenolic content of propolis produced by two Malaysian Stingless Bees, Heterotrigona itama and Geniotrigona thoracica. International Journal of Pharmacognosy and Phytochemical Research, 8(1), 156-161.

Ibrahim, N., Niza, N. F. S. M., Rodi, M. M. M., Zakaria, A. J., Ismail, Z., \& Mohd, K. S. (2016). Chemical and biological analyses of Malaysian stingless bee propolis extracts. Malaysian Journal of Analytical Sciences, 20(2), 413-422.

Isla, M. I., Moreno, M. N., Sampietro, A. R., \& Vattuone, M. A. (2001). Antioxidant activity of Argentine propolis extracts. Journal of Ethnopharmacology, 76(2), 165-170.

Ito, J., Chang, F. R., Wang, H. K., Park, Y. K., Ikegaki, M., Kilgore, N., \& Lee, K. H. (2001). Anti-AIDS agents. 48. Anti-HIV activity of moronic acid derivatives and the new melliferone-related triterpenoid isolated from Brazilian propolis. Journal of Natural Products, 64(10), 1278-1281.

Kahkonen, M. P., Hopia, A. I., Vuorela, H. J., Rauha, J. P., Pihlaja, K., Kujala, T. S., \& Heinonen, M. (1999). Antioxidant activity of plant extracts containing phenolic compounds. Journal of Agricultural and Food Chemistry, 47(10), 3954-3962.

Kalaiselvi, V., Binu, T. V., \& Radha, S. R. (2016). Preliminary phytochemical analysis of the various leaf extracts of Mimusops elengi L. South Indian Journal of Biological Sciences, 2(1), 24-29.

Kedare, S. B., \& Singh, R. P. (2011). Genesis and development of DPPH method of antioxidant assay. Journal of Food Science and Technology, 48(4), 412-422.

Kumazawa, S., Hamasaka, T., \& Nakayama, T. (2004). Antioxidant activity of propolis of various geographic origins. Food Chemistry, 84, 329-339.

Machado, B. A. S., Silva, R. P. D., de Abreu Barreto, G., Costa, S. S., Silva, D. F. D., Brandão, H. N., Rocha, J. L. C. D., Dellagostin, O. A., Henriques, J. A. P., Guez, M. A. U., \& Padilha, F. F. (2016). Chemical composition and biological activity of extracts obtained by supercritical extraction and ethanolic extraction of brown, green and red propolis derived from different geographic regions in Brazil. PLoS One, 11(1), 1-26.

Marcucci, M. C. (1995). Propolis: chemical composition, biological properties and therapeutic activity. Apidologie, 26(2), 83-99.

Marcucci, M. C., \& Bankova, V. (1999). Chemical composition, plant origin and biological activity of Brazilian propolis. Current Topics in Phytochemistry, 2, 115-123.

Massaro, C. F., Katouli, M., Grkovic, T., Vu, H., Quinn, R. J., Heard, T. A., Carvalho, C., Manley-Harris, M., Wallace, H. M., \& Brooks, P. (2014). 
Anti-staphylococcal activity of C-methyl flavanones from propolis of Australian stingless bees (Tetragonula carbonaria) and fruit resins of Corymbia torelliana (Myrtaceae). Fitoterapia, 95, 247-257.

Milojković Opsenica, D., Ristivojević, P., Trifković, J., Vovk, I., Lušić, D., \& Tešić, Ž. (2016). TLC fingerprinting and pattern recognition methods in the assessment of authenticity of poplar-type propolis. Journal of Chromatographic Science, 54(7), 1077-1083.

Mohammadzadeh, S., Sharriatpanahi, M., Hamedi, M., Amanzadeh, Y., Ebrahimi, S. E. S., \& Ostad, S. N. (2007). Antioxidant power of Iranian propolis extract. Food Chemistry, 103(3), 729-733.

Moreira, L., Dias, L. G., Pereira, J. A., \& Estevinho, L. (2008). Antioxidan properties, total phenols and pollen analysis of propolis samples from Portugal. Food and Chemical Toxicology, 46(11), 3482-3485.

Moreno, M. I. N., Isla, M. I., Sampietro, A. R., \& Vattuone, M. A. (2000) Comparison of the free radical-scavenging activity of propolis from several regions of Argentina. Journal of Ethnopharmacology, 71(1-2), 109-114.

Park, Y. K., Alencar, S. M., \& Aguiar, C. L. (2002). Botanical origin and chemical composition of Brazilian propolis. Journal of Agricultural and Food Chemistry, 50(9), 2502-2506.

Piccinelli, A. L., Mencherini, T., Celano, R., Mouhoubi, Z., Tamendjari, A., Aquino, R. P., \& Rastrelli, L. (2013). Chemical composition and antioxidant activity of Algerian propolis. Journal of Agricultural and Food Chemistry, 61(21), 5080-5088.

Popova, M. P., Graikou, K., Chinou, I., \& Bankova, V. S. (2010). GCMS profiling of diterpene compounds in mediterranean propolis from Greece. Journal of Agricultural and Food Chemistry, 58(5), 3167-3176.

Popova, M., Dimitrova, R., Al-Lawati, H. T., Tsvetkova, I., Najdenski, H., \& Bankova, V. (2013). Omani propolis: Chemical profiling, antibacterial activity and new propolis plant sources. Chemistry Central Journal, 7(1) 158.

Rufatto, L. C., Dos Santos, D. A., Marinho, F., Henriques, J. A. P., Ely, M. R. \& Moura, S. (2017). Red propolis: Chemical composition and pharmacological activity. Asian Pacific Journal of Tropical Biomedicine, 7(7), 591-598.

Salmon, T. B., Evert, B. A., Song, B., \& Doetsch, P. W. (2004). Biological consequences of oxidative stress-induced DNA damage in Saccharomyces cerevisiae. Nucleic acids research, 32(12), 3712-3723.

Sforcin, J. M., \& Bankova, V. (2011). Propolis: is there a potential for the development of new drugs? Journal of Ethnopharmacology, 133(2), 253 260.

Shittu, O. K., Lawal, B., Haruna, G. M., Berinyuy, E. B., Yusuf, A. A., \& Ibrahim, A. M. (2015). Hepato-curative effects of methanol extract from Nigeria bee propolis in carbon tetrachloride $\left(\mathrm{CCL}_{4}\right)$ intoxicated rat. Euro J Biotechnol Biosci, 3, 12-6.

Silva-Carvalho, R., Baltazar, F., \& Almeida-Aguiar, C. (2015). Propolis: A complex natural product with a plethora of biological activities that can be explored for drug development. Evidence-Based Complementary and Alternative Medicine, Article ID 206439, 2015.

Singleton, V.L., \& Rossi, J.A. (1965). Colorimetry of total phenolics with phosphomolybdicphosphotungstic acid reagents. American Journal of Enology and Viticulture, 16, 144-158

Socha, R., Gałkowska, D., Bugaj, M., \& Juszczak, L. (2015). Phenolic composition and antioxidant activity of propolis from various regions of Poland. Natural Product Research, 29(5), 416-422.

Sosa, V., Moliné, T., Somoza, R., Paciucci, R., Kondoh, H., \& LLeonart, M. E. (2013). Oxidative stress and cancer: an overview. Ageing Research Reviews, 12(1), 376-390.

Tazawa, S., Warashina, T., Noro, T., \& Miyase, T. (1998). Studies on the constituents of Brazilian propolis. Chemical and Pharmaceutical Bulletin, 46, 1477-1479.

Tazawa, S., Warashina, T., \& Noro, T. (1999). Studies on the constituents of Brazilian propolis II. Chemical and Pharmaceutical Bulletin, 47, 13881392

Trease, G. E. \& Evans, W. C. (1983). Textbook of Pharmacognosy. 12th edn. Balliese Tindall and Company Publisher, London. pp. 343 - 383.

Umthong, S., Phuwapraisirisan, P., Puthong, S., \& Chanchao, C. (2011). In vitro antiproliferative activity of partially purified Trigona laeviceps propolis from Thailand on human cancer cell lines. BMC Complementary and Alternative Medicine, 11(1), 37.

Valente, M. J., Baltazar, A. F., Henrique, R., Estevinho, L., \& Carvalho, M. (2011). Biological activities of Portuguese propolis: protection against free radical-induced erythrocyte damage and inhibition of human renal cancer cell growth in vitro. Food and Chemical Toxicology, 49(1), 86-92.

Viuda-Martos, M., Ruiz-Navajas, Y., Fernández-López, J., \& Pérez-Álvarez, J. A. (2008). Functional properties of honey, propolis, and royal jelly. Journal of Food Science, 73(9), R117-R124.

Woisky, R. \& Salatino, A. (1998). Analysis of propolis:some parameters and procedures for chemical quality control. Journal of Apicultural Research, 37, 99-105.

Wollgast, J. \& Anklam, E. (2000). Review on polyphenols in Theobroma cacao: Changes in composition during the manufacture of chocolate and methodology for identification and quantification. Food Research International, 33, 423-447.

Wu, Y. Y., Li, W., Xu, Y., Jin, E. H., \& Tu, Y. Y. (2011). Evaluation of the antioxidant effects of four main theaflavin derivatives through chemiluminescence and DNA damage analyses. Journal of Zhejiang University Science B, 12(9), 744.

Yamagishi, S. I., \& Matsui, T. (2011). Nitric oxide, a janus-faced therapeutic target for diabetic microangiopathy-Friend or foe?. Pharmacological Research, 64(3), 187-194.

Yang, H., Dong, Y., Du, H., Shi, H., Peng, Y., \& Li, X. ( 2011). Antioxidant compounds from propolis collected in Anhui, China. Molecules, 16, 3444 3455 . 